\title{
Evaluating Effect of Coke Layer Thickness on Permeability by Pressure Drop Estimation Model
}

\author{
Kazuhira ICHIKAWA, ${ }^{*}$ Yusuke KASHIHARA, Nobuyuki OYAMA, Toshiyuki HIROSAWA, Jun ISHII, \\ Michitaka SATO and Hidetoshi MATSUNO
}

Steel Research Laboratory, JFE Steel Corporation, 1 Kawasaki-cho, Chuo-ku, Chiba, 260-0835 Japan.

(Received on July 25, 2016; accepted on November 1, 2016; originally published in Tetsu-to-Hagané, Vol. 102, 2016, No. 1, pp. 1-8)

\begin{abstract}
Recently, low coke rate blast furnace operation has been required in response to the rising cost of coking coal. However, the thickness of the coke layer decreases in low coke rate operation. Since it is known that the gas permeability of the blast furnace deteriorates as the coke layer thickness decreases, it is important to determine the minimum coke layer thickness for stable blast furnace operation. On the other hand, the minimum coke layer thickness has not been clarified due to a lack of equipment capable of measuring the effect of the coke layer thickness on permeability.

In this study, a new experimental device called the cohesive zone simulator was developed to clarify the minimum coke layer thickness. In the cohesive zone, gas flows horizontally along the coke layer. In order to quantify the effect of the coke layer thickness on permeability, this horizontal gas flow should be simulated. Therefore, this simulator simulates a horizontal gas flow.

Next, the effect of the coke layer thickness was quantified by using the cohesive zone simulator. The results showed that melting iron ore penetrated into the coke layer and closed part of the layer. These phenomena caused a deterioration of permeability under thin coke layer thickness conditions.

Finally, a pressure drop estimation model considering penetration of the coke layer by melting ore was developed with the aim of quantifying the minimum coke slit thickness.
\end{abstract}

KEY WORDS: iron making; blast furnace; $\mathrm{CO}_{2}$; low coke rate; coke layer thickness; cohesive zone.

\section{Introduction}

In response to recent increases in the price of coking coal, low coke rate operation of blast furnaces has been required in order to reduce ironmaking costs. Because coke functions not only as a reducing agent, but also as a spacer in the blast furnace, low coke rate operation causes various undesirable phenomena, including deterioration of furnace permeability $^{1)}$, channeling ${ }^{2)}$ and delay of the reduction reaction. In turn, this delay of the reduction reaction causes dropping of unreduced $\mathrm{FeO},{ }^{3)}$ heat shortage and expansion of the cohesive zone. ${ }^{4)}$ Therefore, for stable low coke rate operation, it is necessary to improve permeability and reducibility.

One method to improve permeability and reducibility at the same time is mixed coke charging in the ore layer. This technique has been examined in various laboratory studies. For example, softening tests under load confirmed that the permeability of a softening sinter layer containing mixed coke was improved by generation of local spaces around the mixed coke, ${ }^{4-6)}$ and that reducibility was improved by promotion of the reaction between the ore and mixed coke. ${ }^{7-10)}$ In a gas flow analysis using a DEM-DFD, a $50 \%$ coke mixed condition showed the lowest pressure drop,

\footnotetext{
* Corresponding author: E-mail: ka-ichikawa@jfe-steel.co.jp DOI: http://dx.doi.org/10.2355/isijinternational.ISIJINT-2016-459
}

especially in low coke rate operation. ${ }^{11)}$

Coke mixed charging is used in some blast furnaces. For example, Anan et al. studied the effect of small coke mixed charging at Oita No. 1 and No. 2 blast furnaces, and confirmed that the reducing agent rate decreased with 50 $\mathrm{kg} / \mathrm{t}$ small coke mixed charging due to improvement of the indirect reduction reaction. ${ }^{12)}$ Sawayama et al. confirmed improvement of the gas utilization ratio and permeability when the mixed coke ratio was increased from $15 \mathrm{~kg} / \mathrm{t}$ to $30 \mathrm{~kg} / \mathrm{t}$ at Kakogawa No. 3 blast furnace. ${ }^{13)}$ Watakabe et al. also studied the effect of $120 \mathrm{~kg} / \mathrm{t}$ mixed coke charging at Chiba No. 6 blast furnace, and confirmed a decrease in the coke rate due to an increased gas utilization ratio, decreased heat loss and stable permeability in the lower part of the furnace. ${ }^{4}$ These studies showed that coke mixed charging is an effective technique for achieving stable low coke rate operation.

By contrast, mixed coke charging operation has possibility that cause deterioration of permeability. Mixed coke charging operation results in a relative decrease in the coke layer because the amount of coke charged to the coke layer is reduced. Since the coke layer functions as a gas path, a thinner coke layer reduces permeability. Ichida et al. studied the effect of the coke layer thickness on permeability at Muroran No. 2 blast furnace. ${ }^{1)}$ They confirmed that permeability decreased when the average lump coke layer thick- 
ness was less than $190 \mathrm{~mm}$ in the belly zone. ${ }^{1)}$ This result shows that the coke layer thickness is an important factor for stable blast furnace operation, and indicates that there is a minimum coke layer thickness for maintaining stable operation. Nevertheless, the effect of the coke layer thickness on the permeability of a blast furnace had not been studied theoretically. Especially in mixed coke charging operation, the minimum coke layer thickness seems to be different from that in conventional charging because the permeability of the cohesive zone is improved by mixed coke charging. ${ }^{4)}$ Therefore, it is important to elucidate the mechanism of the minimum coke layer thickness and clarify the minimum coke layer thickness in mixed coke charging.

The results of measurements of the shape of the cohesive zone in dissected blast furnaces (Higashida No. 1 blast furnace, Hirohata No. 1 blast furnace and Kukioka No. 4 blast furnace) revealed that the ore layer and coke layer were alternately layered in all of the furnaces studied. ${ }^{14)}$ Therefore, in the cohesive zone, gas is expected to flow horizontally following the coke layer. This is caused by the reduced permeability of the ore layer due to softening of the ore at temperatures over $1200^{\circ} \mathrm{C}$. ${ }^{4)}$ Thus, it is important to develop new equipment which can simulate this type of horizontal gas flow in order to quantify the effect of the coke layer thickness on permeability.

Based on the background outlined above, the purposes of this study are as follows: First, a new simulator which can simulate the horizontal gas flow was developed. Second, the effect of the coke layer thickness on permeability was studied by using this simulator, and a pressure drop estimation model was developed. Further, the proper coke layer thickness under a mixed coke charging condition was quantified by using this model, and the result was applied to blast furnace operation.

\section{Development of Cohesive Zone Simulator}

Figure 1 shows a schematic drawing of the cohesive zone

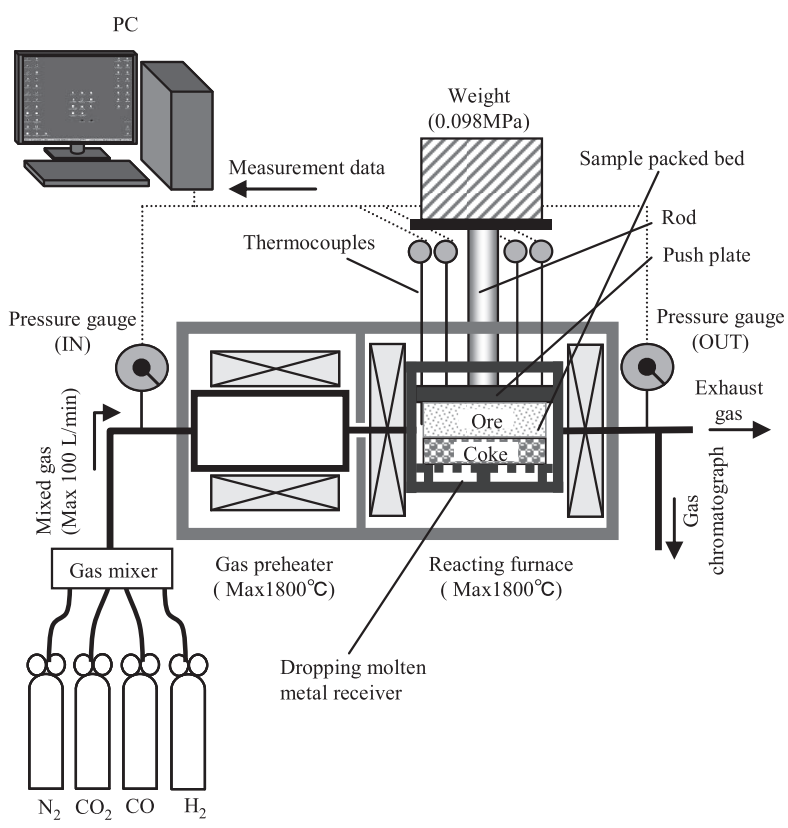

Fig. 1. Schematic drawing of cohesive zone simulator. simulator developed in this study. This simulator consists of a gas preheater and a reacting furnace. The gas used in this experiment was mixed by the gas mixer, and then heated by the gas preheater. This preheated gas was injected into the sample bed from the side, and the gas traveled through the sample bed horizontally. Outlet gas was collected and its composition was analyzed with a gas chromatograph, and the measured data were transmitted to a personal computer. The data included the pressure obtained by the pressure gauges, the temperature obtained by the thermocouples and the sample bed shrinkage rate. The sample bed, which consisted of alternately packed ore and coke layers, was set in the reacting furnace. The maximum load of $0.098 \mathrm{MPa}$ was applied to the sample bed from the top by the rod. Preheated gas was injected horizontally into this sample bed. To prevent gas leakage from the packed bed, a seal plate was set on the top of the packed bed. During experiments, the generated molten iron was collected in the dropping molten iron receiver. Three gas deflector plates were installed in the receiver to prevent gas from passing through this receiver. These devices were designed so that the gas could only pass through the packed bed without gas leaks. The effect of the coke layer thickness on permeability in the cohesive zone was studied by using the cohesive zone simulator developed in this study.

\section{Effect of Coke Layer Thickness on Permeability by Cohesive Zone Simulator}

\subsection{Experimental Conditions}

The effect of the coke layer thickness on permeability was studied by using the cohesive zone simulator. Figure 2 shows the experimental conditions of the packed bed. The width and length of the packed bed were $50 \mathrm{~mm}$ and 350 $\mathrm{mm}$, respectively. First, in order to clarify the effect of the coke layer thickness on permeability, the coke layer thickness was changed to 13,20 and $40 \mathrm{~mm}$. Then, in order to quantify the effect of the mixed coke ratio on permeability, the mixed coke ratio was changed to 0,9 and $13 \mathrm{wt} \%$. The total amounts of ore and coke were constant under all conditions, being $1448 \mathrm{~g}$ of ore and $302 \mathrm{~g}$ of coke. These values were decided so that the total coke rate was $320 \mathrm{~kg} / \mathrm{t}-\mathrm{p}$. The ore diameter was $5.5 \mathrm{~mm}$, and the coke diameter was $10 \mathrm{~mm}$. In this study, the ore was prereduced to $33 \%$ to simulate the reduction ratio of ore at $1000^{\circ} \mathrm{C}$ in the blast

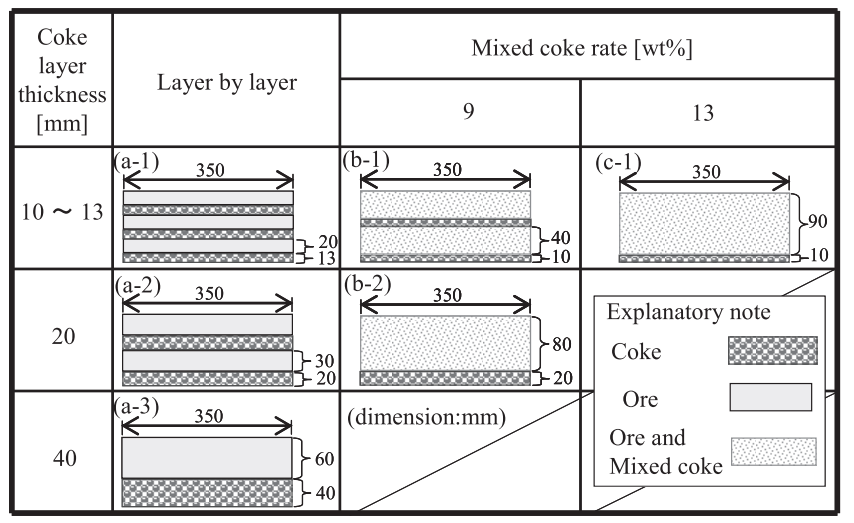

Fig. 2. Experimental conditions of packed bed. 
furnace. The maximum coke layer thickness was $40 \mathrm{~mm}$ without mixed coke, $20 \mathrm{~mm}$ with the mixed coke ratio of $9 \mathrm{wt} \%$, and $10 \mathrm{~mm}$ with the mixed coke ratio of $13 \mathrm{wt} \%$. During the experiment, the load of $0.098 \mathrm{MPa}$ was applied to the sample from the top by the rod. Figure 3 shows the experimental conditions of the temperature and gas composition. In order to simulate the ore melting behavior in the cohesive zone, the sample was heated in a $\mathrm{N}_{2}$ atmosphere to $1000^{\circ} \mathrm{C}$, and over $1000^{\circ} \mathrm{C}$, the temperature increase rate and gas composition simulated the bosh of the blast furnace. The gas flow rate was $100 \mathrm{~L} / \mathrm{min}$. (standard temperature and pressure). During the experiment, pressure drop was measured by the pressure gauges. The cross section of the sample quenched at $1400^{\circ} \mathrm{C}$ was observed, and EPMA analysis of quenched samples was also performed.

\subsection{Experimental Results}

\subsubsection{Pressure Drop in Layered Condition}

The pressure drop of a packed bed without mixed coke was measured. Figure 4 shows the measured results of the change in pressure drop with temperature. With each coke layer thickness, pressure drop increased with increasing temperature. Compared with the pressure drop of the $40 \mathrm{~mm}$ coke layer, the pressure drop with the $13 \mathrm{~mm}$ thickness was higher at temperatures over $1200^{\circ} \mathrm{C}$, and the pressure drop with the $20 \mathrm{~mm}$ thickness was higher over $1300^{\circ} \mathrm{C}$. These results indicated that pressure drop increased with decreasing coke layer thickness.

In order to study the behavior of the sample bed at $1400^{\circ} \mathrm{C}$, the cross sections of quenched samples were observed. Figure 5 shows cross-sectional photos before and after the experiment. After the experiment, the ore had melted and some of the melted ore had penetrated into the coke layer. Figure 6 shows a cross-sectional image of the ore-coke interface, together with EPMA images. It is clear that melting ore penetrated into the interparticle spaces between the coke. In addition, the penetrated ore contained large amounts of $\mathrm{Ca}$ and $\mathrm{Si}$, suggesting that a molten slag component penetrated into the spaces between the coke. In observation of the cohesive zone in dissected blast furnaces such as Hirohata No. 1 blast furnace ${ }^{15)}$ and Jenice No. 2 blast furnace, ${ }^{16)}$ there were icicle-like semi-molten materials extending from the bottom of the cohesive zone into the coke layer. Koch et al. presumed that this icicle-like molten slag was formed by penetration of the molten slag into the coke layer. ${ }^{16)}$ Nogueira et al. studied in-situ ore melting

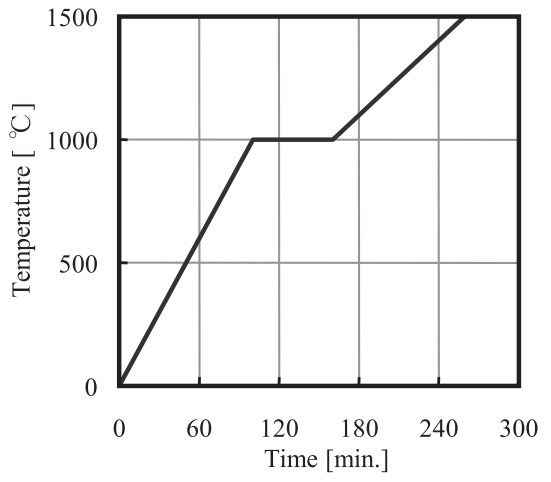

(a) Temperature behavior during softening and loading tests by X-ray transmission observation, and confirmed that molten material penetrated into the orifice at the bottom of the crucible at temperatures over $1230^{\circ} \mathrm{C} .{ }^{17)}$ From these previous studies, it was clear that melting ore penetrated into the coke layer

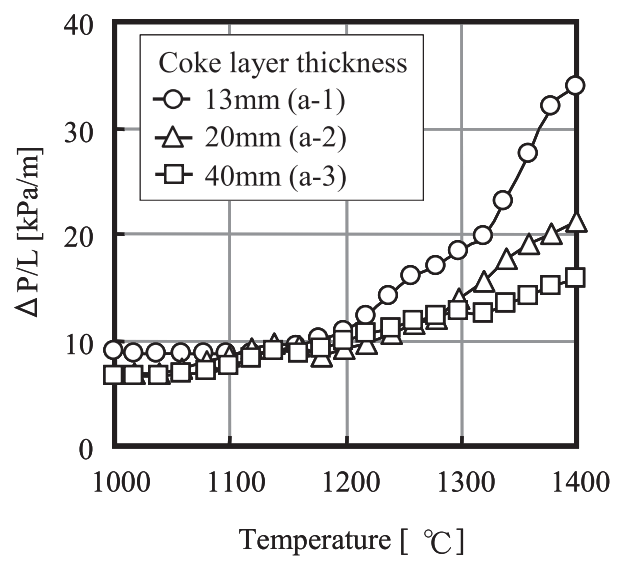

Fig. 4. Measurement results of $\Delta \mathrm{P} / \mathrm{L}$ with temperature.

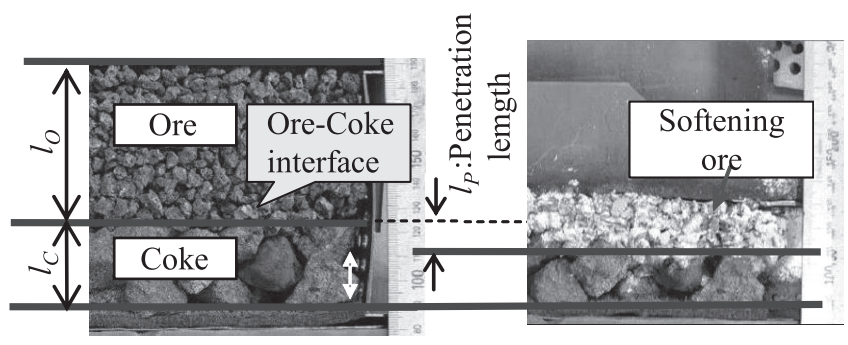

(a) Before

(b) After

Fig. 5. Photo of samples before and after experiment.
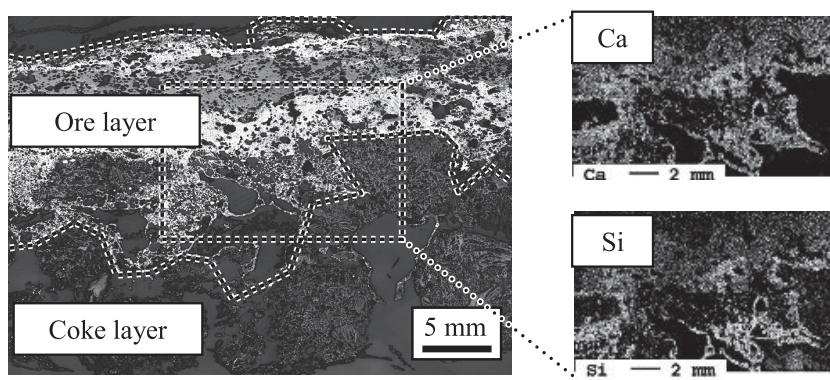

Fig. 6. Cross sectional image of ore coke interface and EPMA image.

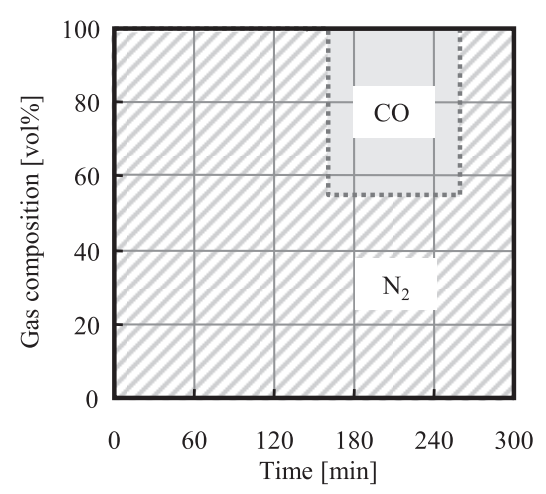

(b) Gas composition

Fig. 3. Experimental conditions of temperature and gas composition. 
and then closed part of the coke layer.

Once melting ore penetrated into coke layer, part of void in coke layer was closed and permeability was deteriorated. Thus, in order to clarify the effect of penetrating ore layer thickness on permeability, the penetrating layer thickness of the melting ore was measured with various coke layer thicknesses. The penetrating layer thickness was obtained from the difference between the coke layer thickness before and after the experiment. The coke layer thickness after the experiment was measured as follows: First, the crosssectional surface area was obtained by cross-sectiontal image analysis, and the obtained surface area was then divided by the horizontal length of the sample bed (350 $\mathrm{mm})$. As the results, the penetrating thickness per ore-coke interface was $4.4 \mathrm{~mm} /$ interface, and it depended not on coke layer thickness. In that case, coke layer closed ratio increased with decreasing initial coke layer thickness. Here, coke layer closed ratio was dividing the difference between coke layer thickness before and after the experiment by coke layer thickness before experiment. Figure 7 shows the relationship between the coke layer thickness before experiment and coke layer closed ratio. Closed ratio increased with deceasing coke layer thickness before experiment. Thus, this penetrating layer of melting ore deteriorated permeability under a thin coke layer condition.

The effect of the coke diameter on the penetrating layer thickness was also studied. The penetrating thickness was measured with the coke diameters of $19 \mathrm{~mm}$ and $27 \mathrm{~mm}$. Figure 8 shows the relationship between the coke diameter and the penetration thickness per ore-coke interface. It is clear that the penetrating thickness increased in direct ratio to the coke diameter. Therefore, the dimensionless penetrating thickness, which was obtained by dividing the penetrating thickness by the coke diameter, was used in this study. The value of the dimensionless penetrating thickness was 0.44 under the condition without mixed coke.

\subsubsection{Effect of Mixed Coke on Permeability}

The effect of the mixed coke on permeability was studied with the mixed coke ratios of 0,9 and $13 \mathrm{wt} \%$. The packed bed conditions are shown in Fig. 2. Figure 9 shows the pressure drop change with temperature. With the mixed coke ratio of $9 \mathrm{wt} \%$, the pressure drop of the $10 \mathrm{~mm}$ coke

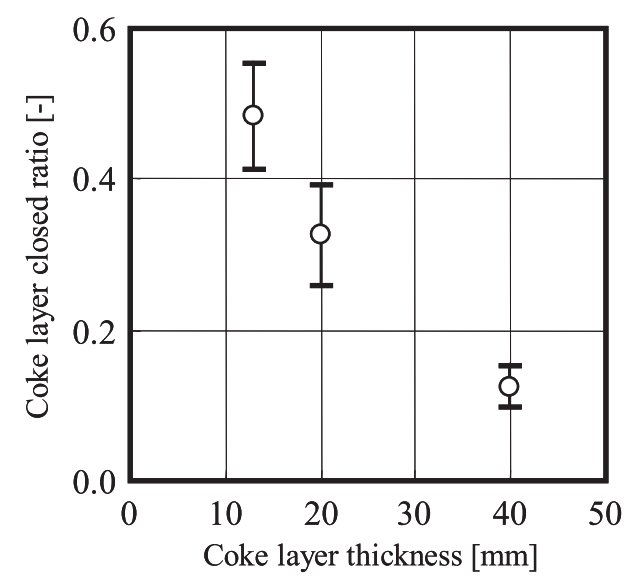

Fig. 7. Relationship between number of interface and summation of penetration thickness. layer was larger than that of the $20 \mathrm{~mm}$ coke layer. On the other hand, pressure drop decreased as the mixed coke ratio increased when the coke layer thickness was $10 \mathrm{~mm}$. This result indicated that permeability was improved by mixed coke. $^{5-7)}$

To quantify the effect of mixed coke on the melting ore penetrating thickness, the penetrating thickness was measured by cross-sectional analysis under the condition of coke mixing. Figure 10 shows the relationship between the mixed coke ratio and the penetrating thickness per orecoke interface. The penetrating thickness decreased as the mixed coke rate increased. This result indicated that mixed coke suppressed melting ore penetration. Matsuhashi et al. performed a simulation of the softening and loading test by using a DEM-CFD model, and clarified the fact that coke functions as an aggregate and the load on the melting ore decreased with increasing mixed coke ratio. ${ }^{11)}$ Similarly, in the present experiment, the load on the melting ore layer decreased as the mixed coke ratio increased, and the penetrating layer thickness decreased under the mixed coke condition. From the above, the dimensionless penetrating thickness was obtained by the results of Fig. 10. First, effect of mixed coke ratio on penetrating thickness was linearly approximated. Then obtained approximation formula was divided by coke diameter. As the result, the dimensionless

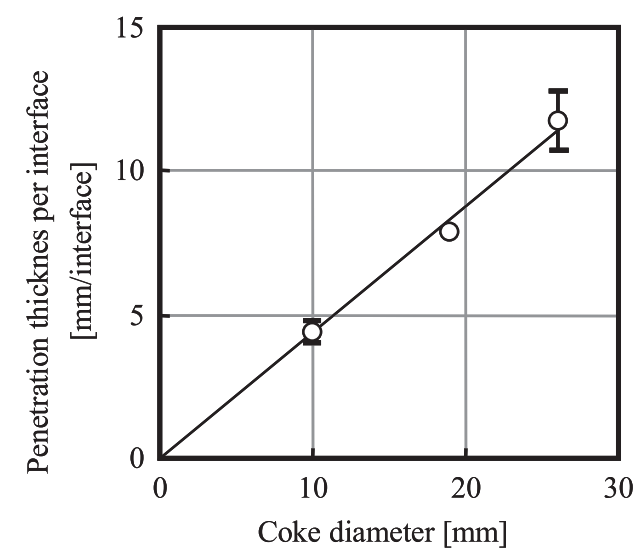

Fig. 8. Relationship between coke diameter and penetration thickness

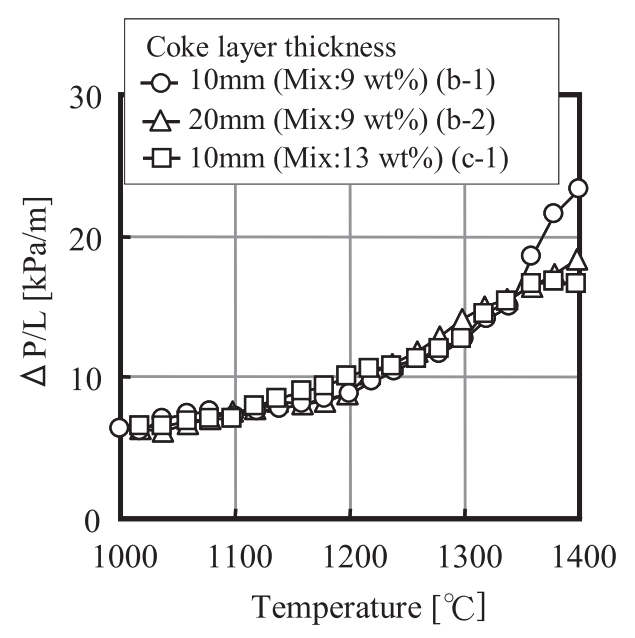

Fig. 9. Measurement results of $\Delta \mathrm{P} / \mathrm{L}$ with temperature. 


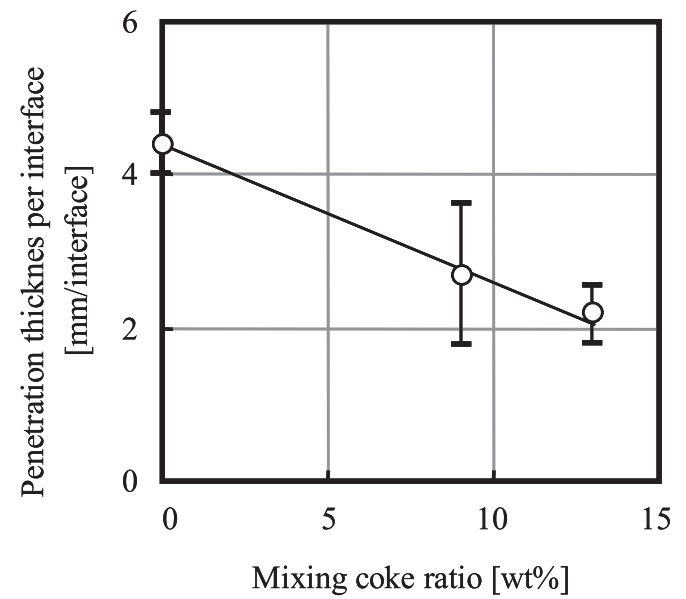

Fig. 10. Relationship between mixed coke rate and penetration thickness per interface.

penetrating thickness is expressed by Eq. (1).

$$
L_{P}^{*}=\frac{L_{P}}{D c}=-1.8 \times 10^{-5} \mathrm{~m}+4.4 \times 10^{-4}
$$

\subsection{Quantification of Effect of Coke Layer Thickness on Pressure Drop}

A pressure drop estimation model was developed considering the penetrating layer, in order to quantify the effect of the coke layer thickness on permeability. The pressure drop at $1400^{\circ} \mathrm{C}$ was estimated with this model and compared with the results of the cohesive zone simulator. Figure 11 shows a outline of the model simulating the cohesive zone simulator. To simplify the model, the ore layer, coke layer and penetrating layer were treated as one layer each. The sum of each layer was obtained by the product of the number of layers and the layer thickness after examination. In the lowest coke layer, a penetrating layer was generated only at the upper surface of the layer. Except in this lowest coke layer, penetrating layers were generated at both the upper and lower surfaces of the coke layer. Thus, assuming $n_{l}$ is the number of coke layers, there were $2 n_{l}-1$ penetrating layers. From the above, the sum of each layer thickness were expressed by Eqs. (2)-(4).

$$
\begin{gathered}
L_{O}=n_{l} \cdot l_{O} \ldots \\
L_{C}=n_{l} \cdot l_{C} \ldots \\
L_{P}=\left(2 n_{l}-1\right) \cdot l_{P}
\end{gathered}
$$

The physical properties of the penetrating layer, such as the particle diameter and void fraction, were treated as the same as those of the melting ore layer. Thus, in this model, thickness of ore layer increased of $L_{p}$, and thickness of coke layer decraased of $L_{p}$.

The pressure at both ends of the coke layer and the ore layer were same. Therefore, the pressure drop of the coke layer was the same that of the ore layer, as shown by Eq. (5).

$$
\left(\frac{\Delta P}{L}\right)_{\text {packed-bed }}=\left(\frac{\Delta P}{L}\right)_{\text {coke }}=\left(\frac{\Delta P}{L}\right)_{\text {soft }}
$$

In Eq. (5), the injected gas was partitioned so that the pres-

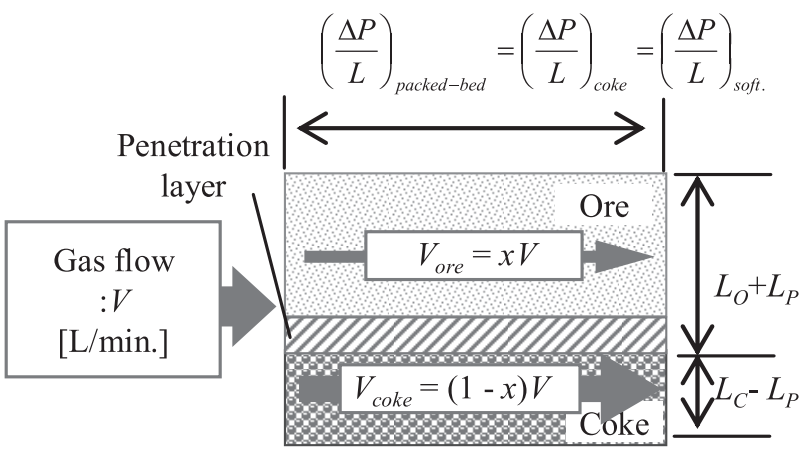

Fig. 11. Schematic view of the model that simulate cohesive zone simulator.

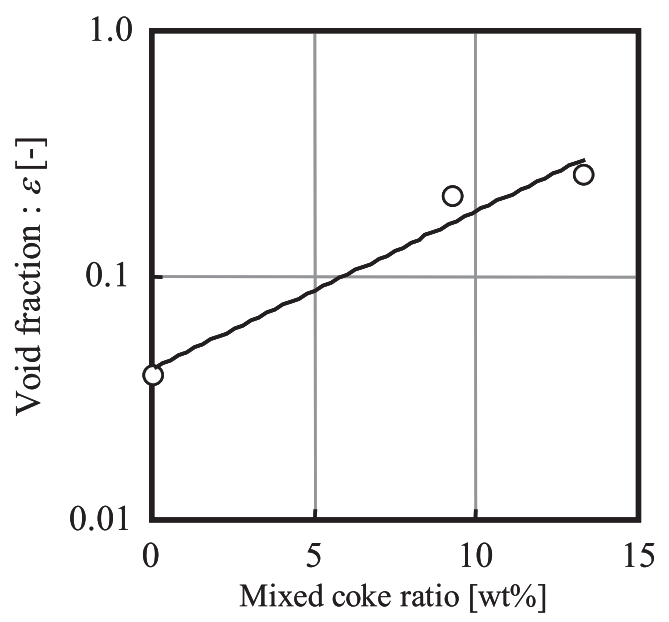

Fig. 12. Relationship between mixed coke ratio and void fraction: $\varepsilon$

sure drop of the coke layer was same as that of the ore layer. The pressure drop of each layer was calculated by the Ergun equation, which is shown by Eq. (6).

$$
\frac{\Delta P}{L}=150 \frac{(1-\varepsilon)^{2}}{\varepsilon^{3}} \cdot \frac{\mu}{\left(\phi \cdot d_{P}\right)^{2}} \cdot u+1.75 \frac{(1-\varepsilon)}{\varepsilon^{3}} \cdot \frac{\rho}{\left(\phi \cdot d_{P}\right)} \cdot u^{2}
$$

In order to quantify the pressured drop of packed bed, difining the value of particle diameters, void fractions and shape factors of the coke and ore layers was necessary. In this model, the coke diameter was $10 \mathrm{~mm}$, the void fraction was 0.418 and the shape factor was 0.785 . The void fraction and shape factor were the values obtained by Yamada et al. on the condition that the coke diameter was $10 \mathrm{~mm} .{ }^{18)}$ The particle diameter in the melting ore layer was $5.5 \mathrm{~mm}$. Figure 12 shows the relationship between the mixed coke ratio and the void fraction. These values were obtained by fitting the experimental results and calculated results. These results indicate that the void fraction of the melting ore layer increased with the mixed coke ratio. The effect of mixed coke ratio on void fraction was approximated by the results of Fig. 12, and is expressed by Eq. (7).

$$
\varepsilon_{\text {soft }}=0.043 \cdot \exp (0.15 \mathrm{~m})
$$

Figure 13 shows a comparison of the measurement results and calculation results. The calculation results show good agreement with the measurement results. Thus, it was confirmed that the penetrating layer thickness increased 
as the coke layer thickness decreased, and this caused an increasing pressure drop. Additionally, the increase in the pressure drop with a thicker coke layer thickness was moderated by an increased mixed coke ratio. There are assumed to be two reasons for this. First, melting ore penetration was moderated by the higher mixed coke ratio, as shown by Eq. (1), and second, the permeability of the melting ore layer was increased by the larger amount of mixed coke. To confirm this assumption, effect of mixed coke layer on gas partition ratio for coke layer was calculated by using the model shown in Fig. 11. Calculating conditions were as follow, the coke layer thickness was $40 \mathrm{~mm}$ without mixed coke, $20 \mathrm{~mm}$ with the mixed coke ratio of $9 \mathrm{wt} \%$, and 10 mm with the mixed coke ratio of $13 \mathrm{wt} \%$. Figure 14 shows the calculation results. The gas partition ratio of the coke layer decreased as the mixed coke ratio increased. This is because the permeability of the melting layer was improved by increasing the mixed coke ratio, and more gas passed through the melting ore layer. On the other hand, the amount of gas flow through the coke layer decreased as the mixed coke ratio increased, and as a result, the deterioration of permeability caused by the penetrating layer was moderated.

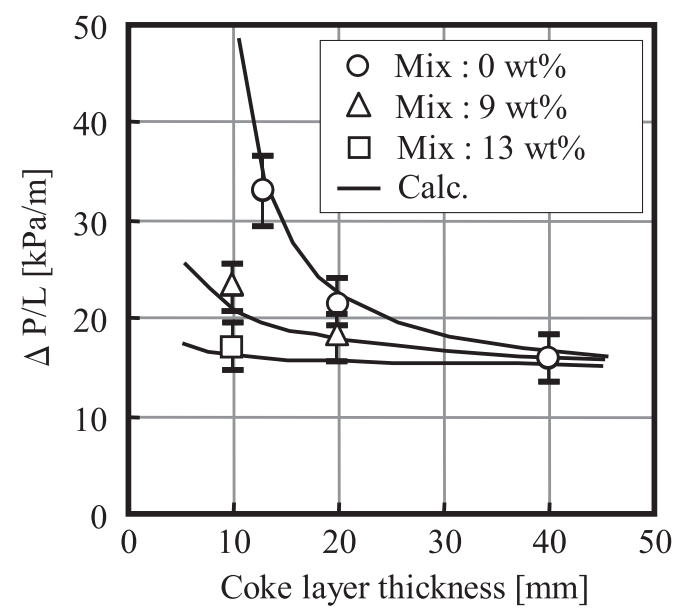

Fig. 13. Comparison between measurement results and calculation results of $\Delta \mathrm{P} / \mathrm{L}$.

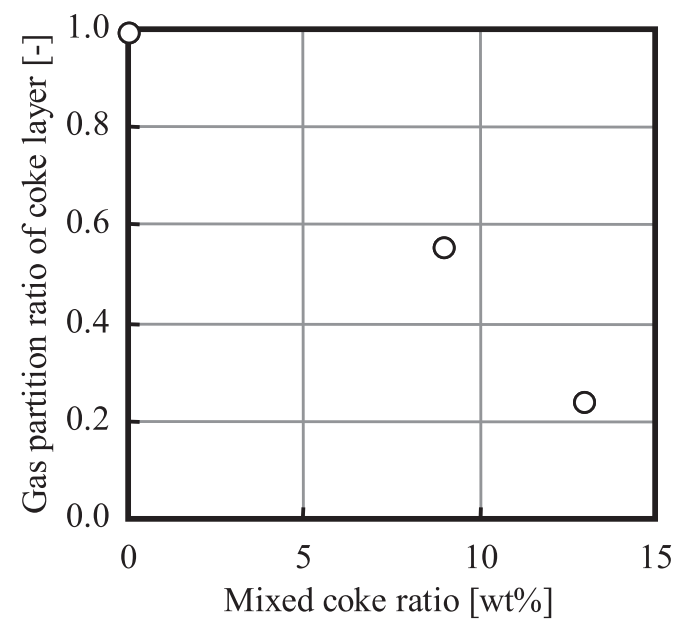

Fig. 14. Relation ship between gas partition ratio of coke layer and mixed coke ratio.

\section{Development of Pressure Drop Estimation Model for Blast Furnace}

\subsection{Development of Pressure Drop Estimation Model}

4.1.1. Outline

A pressure drop estimation model was developed in order to quantify the minimum coke layer thickness depending on the mixed coke ratio. This model considers the lumpy zone and the cohesive zone. Figure 15 shows the structure of the cohesive zone targeted in the calculation. The model of the lumpy zone was considered as a layered model consisting of alternating coke and ore layers. Gas with a predetermined flow rate was injected from the bottom in this model, and the pressure drop at that time was quantified. The model of the cohesive zone was based on the model developed by Kashihara et al. ${ }^{19)}$ In this model, the radial layer thickness and the mixed coke ratio distribution were assumed to be flat in order to simplify the model. The dimensions of the cohesive layer and the ore layer were $1 \mathrm{~m}$ in width $\times 1 \mathrm{~m}$ in depth. Coke layers were arranged at the lower part of the cohesive layer and the ore layer. Gas with a velocity simulating the belly part of the blast furnace was injectd from the lower part in this model, and the pressure drop of the cohesive zone was quantified. In this model, changes in particle diameter due to reaction were not considered. The coke layer thickness was an arbitrary value. The thicknesses of the cohesive layer and ore layer were determined by the coke layer thickness and coke rate. The property of penetrating layer was treated as a melting ore layer, as in the model shown in Fig. 11. Thus, the thickness of the melting ore layer increased in proportion to the penetrating thickness $L_{P}$, and the coke layer thickness decreased in proportion to $L_{P}$. In this model, two gas routes were considered, one passing through only the melting ore layer, and the other passing through the ore layer after passing through the coke layer. The injected gas was partitioned so that the pressure drop of both routes became the same, as shown by Eq. (8).

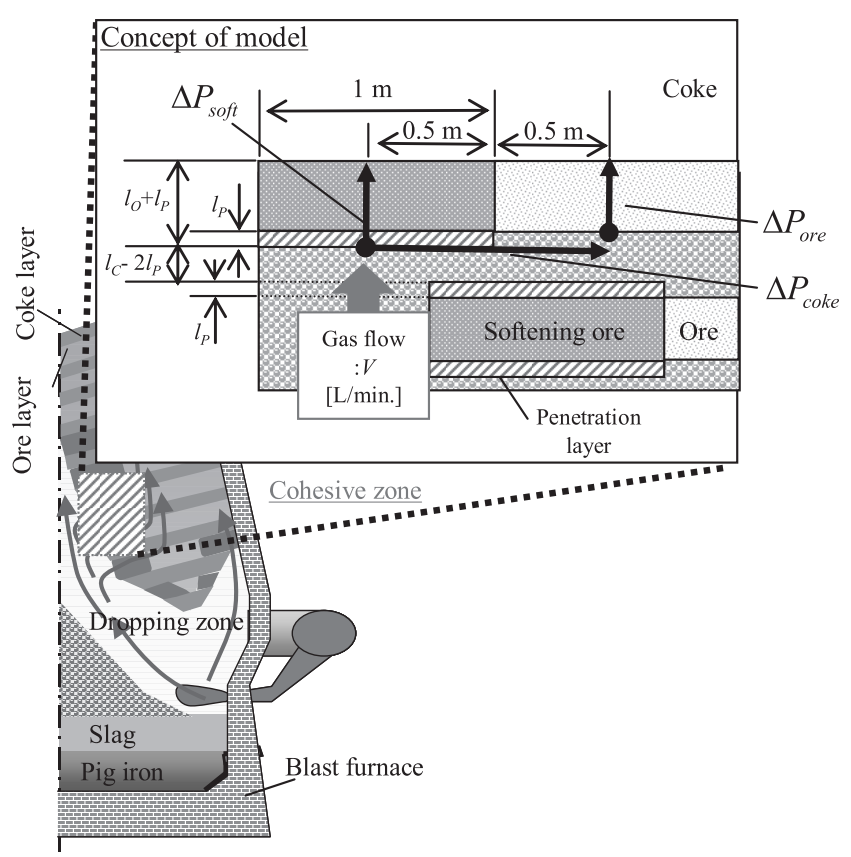

Fig. 15. Structure of cohesive zone targeted in calculation. 


$$
\Delta P_{\text {soff }}=\Delta P_{\text {coke }}+\Delta P_{\text {ore }}
$$

The pressure drop of each route was calculated by the Ergun equation, which was shown previously as Eq. (6).

\subsubsection{Estimation of Physical Properties}

In order to estimate pressure drop by the model shown in Fig. 16, it is necessary to determine values such as the particle diameter, shape factor and void fraction of the layer. The particle size of the coke and ore were decided based on the results of sampling of an actual blast furnace. The harmonic mean diameter of the coke was $0.032 \mathrm{~m}$. The void fraction and shape factor were calculated by the formulas in the study by Yamada et al. ${ }^{18)}$ as a void fraction of 0.42 and shape factor of 0.785 . The diameter and void fraction of the ore layer were measured values obtained under the condition of coke mixing. Table 1 shows the measured results of the diameter and void fraction of the ore layer. The diameter of the mixed coke was larger than that of the ore. Thus, the harmonic mean diameter of the ore layer with mixed coke increased as the mixed coke ratio increased. On the other hand, the void fraction of the ore layer decreased as the mixed coke ratio increased, because the particle size

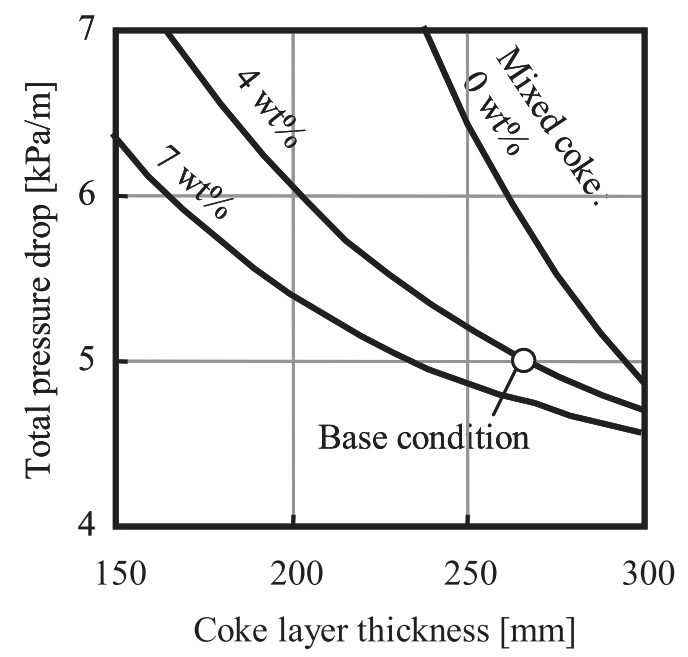

Fig. 16. Calculated results of relationship between total pressure drop and coke layer thickness.

Table 1. Diameter of ore and void fraction of ore layer.

\begin{tabular}{cccc}
\hline \multicolumn{4}{c}{ Mixed coke ratio (wt\%) } \\
\hline & 0 & 4 & 7 \\
\hline $\mathrm{d}_{\text {mix }}(\mathrm{m})$ & 0.010 & 0.011 & 0.012 \\
$\varepsilon_{\text {mix }}(-)$ & 0.28 & 0.25 & 0.24 \\
\hline
\end{tabular}

Table 2. Calculating condition.

\begin{tabular}{cccc}
\hline & & Lumpy zone & Cohesive zone \\
\hline Height of zone & $(\mathrm{m})$ & 17 & 2 \\
Temperature & $\left({ }^{\circ} \mathrm{C}\right)$ & 720 & 1300 \\
Pressure & $(\mathrm{MPa})$ & 0.33 & 0.38 \\
Gas velocity & $(\mathrm{m} / \mathrm{s})$ & 0.7 & 1.0 \\
\hline
\end{tabular}

distribution of the ore layer with mixed coke was increased by the mixed coke. The diameter of particle in the cohesive layer was treated as the same as that of the ore layer. The void fraction of the cohesive layer was calculated by Eq. (7), which was obtained from the results of the cohesive zone simulator test.

In this model, 2 zones were considered, lumpy zone and cohesive zone. In order to calculate the average pressured drop, the heights of these zones were necessary. Temperature and pressure of both zone were also necessary, to estimate the gas property. Thus, the height, average temperature and average pressure of the lumpy zone and the cohesive zone were decided by a 2-dimensional stationary blast furnace model. ${ }^{20)}$ Table 2 shows the results. These values were applied to the pressure drop estimation model developed in this study.

\subsection{Application to Blast Furnace Operation}

Figure 16 shows the calculated results of the relationship between total pressure drop and the coke layer thickness in the belly part of a blast furnace. Calculating conditions was the coke rate is $360 \mathrm{~kg} / \mathrm{t}$ and the mixed coke ratio was 0 , 4 or $7 \mathrm{wt} \%$. Pressure drop increased with decreasing coke layer thickness. On the other hand, pressure drop decreased as the mixed coke ratio increased. Based on this result, the coke layer thickness in the belly of a blast furnace with an inner volume of $5000 \mathrm{~m}^{3}$ was $260 \mathrm{~mm}$ when the mixed coke ratio was $4 \mathrm{wt} \%$. In order to operate with the mixed coke ratio of $7 \mathrm{wt} \%$ while maintaining a pressure drop equal to or less than that with $4 \mathrm{wt} \%$, the coke layer thickness in the blast furnace belly must be more than $230 \mathrm{~mm}$. On the other hand, from the existing research, it is known that the average reduction ratio decreases as the ore layer thickness increases. ${ }^{21)}$ Under a constant coke rate condition, the ore layer thickness increases with increasing coke layer thickness, and this deteriorates both the reducibility of the ore layer and the reducing agent rate. These studies suggest that there is a proper coke layer thickness to minimize pressure drop. Thus, to achieve stable blast furnace operation, it is necessary to decrease the coke layer thickness within the range which prevents increasing pressure drop while also maintaining the reducibility of the ore layer.

By using this result, operating test was done. For the above reasons, in order to prevent permeability deterioration due to a thick coke layer thickness and deterioration of reducibility due to a thin ore layer thickness, the coke layer thickness was decided to be $240 \mathrm{~mm}$ and the mixed coke ratio was increased from 4 to $7 \mathrm{wt} \%$, at the blast furnace with an inner volume of $5000 \mathrm{~m}^{3}$ class. In this test, $4 \mathrm{wt} \%$ of the coke was small coke and the other $3 \mathrm{wt} \%$ was lumpy coke. Productivity was $2.0 \mathrm{t} / \mathrm{day} / \mathrm{m}^{3}$ during the test. Figure 17 shows a comparison between the base period and the test period. In this figure, the vertical axis is the pressure drop index. ${ }^{22)}$ By maintaining the proper coke layer thickness, it was possible to maintain a constant pressure drop under the condition of coke mixing. Based on this result, it was confirmed that maintaining the proper coke layer thickness contributes to achieving stable blast furnace operation. 


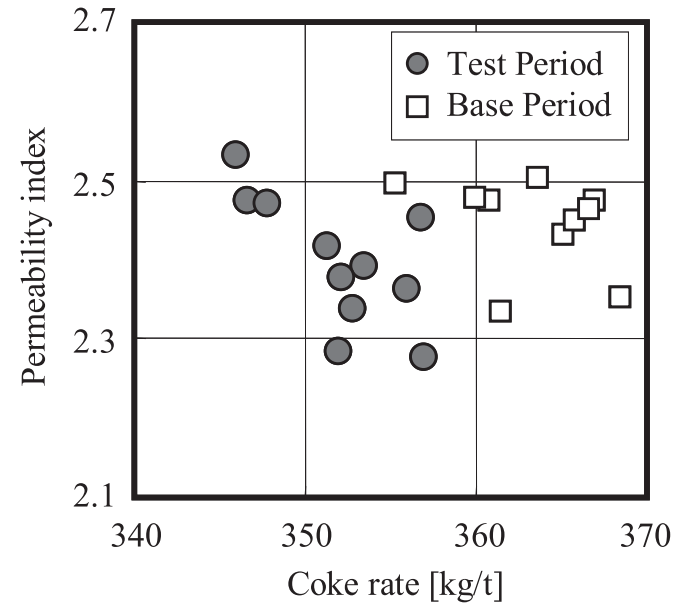

Fig. 17. Comparison between base period and test period.

\section{Conclusion}

In this study, first, a cohesive zone simulator which simulates the typical horizontal gas flow that occurs in the blast furnace cohesive zone was developed. The effect of the coke layer thickness on permeability was studied by using this cohesive zone simulator, and a pressure drop estimation model was developed based on the results of cohesive zone simulator tests. The minimum coke layer thickness depending on the mixed coke ratio was then quantified by using this model. The following conclusions were obtained.

(1) Pressure drop increased with decreasing coke layer thickness. This is attributed to the fact that the number of coke-ore interfaces in the packed bed increased as the coke layer thickness became thinner, resulting in an increase in the total thickness of the penetrating layer of melting ore into the coke layers and a corresponding decrease in the gas-permeable coke slit.

(2) The penetrating layer thickness decreased as the mixed coke ratio increased. As a result, penetration of melting ore into the coke layer decreased, and the increase in pressure drop due to the thinner coke layer was moderated.

(3) The results of the pressure drop estimation model and actual blast furnace operation confirmed that maintaining the proper coke layer thickness contributes to achieving stable blast furnace operation.

\section{Nomenclature}

$d_{P}:$ Particle diameter [m]

$g$ : Acceleration of gravity $\left[\mathrm{m} / \mathrm{s}^{2}\right]$

$L: \quad$ Sample layer thickness [m]

$L_{C}: \quad$ Coke layer thickness [m]

$L_{C, \min }: \quad$ Minimum coke layer thickness [m]

$L_{O}:$ Ore layer thickness $[\mathrm{m}]$

$L_{P}: \quad$ Penetrating thickness [m]
$L_{P}^{*}$ : Dimensionless penetrating thickness [-]

$l_{C}$ : One coke layer thickness in cohesive zone simulator $[\mathrm{m}]$

$l_{O}$ : One ore layer thickness in cohesive zone simulator [m]

$l_{P}$ : Penetrating layer thickness in cohesive zone simulator $[\mathrm{m}]$

$m$ : $\quad$ Mixed coke ratio [wt $\%$ ]

$n_{i}$ : Number of coke-ore interfaces in cohesive zone simulator [-]

$n_{l}$ : Number of coke layers in cohesive zone simulator $[-]$

$\Delta P: \quad$ Pressure drop $[\mathrm{Pa}]$

$u$ : Gas velocity $[\mathrm{m} / \mathrm{s}]$

$\varepsilon$ : Void fraction [-]

$\rho:$ Density $\left[\mathrm{kg} / \mathrm{m}^{3}\right]$

$\mu$ : Viscosity $[\mathrm{Pa} \cdot \mathrm{s}]$

$\phi$ : Shape factor [-]

$\xi$ : Gas partition ratio [-]

\section{REFERENCES}

1) M. Ichida, S. Matsuzaki, T. Tanaka and F. Koizumi: Tetsu-toHagané, 87 (2001), 342.

2) H. Kawata, S. Kishimoto, A. Maki, Y. Saijyo, H. Wakai and K. Yamamoto: Tetsu-to-Hagané, 79 (1993), T5.

3) S. Kajikawa, R. Yamamoto, R. Nakajima, T. Kishimoto and T. Fukushima: Tetsu-to-Hagané, 68 (1982), 2361.

4) S. Watakabe, K. Takeda, H. Nishimura, S. Goto, N. Nishimura, T. Uchida and M. Kiguchi: ISIJ Int., 46 (2006), 513.

5) H. Kokubu, K. Sato, Y. Konishi, S .Taguchi, S. Sakurai, K. Okumura and K. Ichifuji: Tetsu-to-Hagané, 70 (1984), S50.

6) H. Hotta, H. Taninaka, R. Yamamoto and S. Kishimoto: Tetsu-toHagané, 70 (1984), S814.

7) M. Gono, K. Iwatsuki, M. Takasaki, K. Nojima and T. Miwa: Tetsuto-Hagané, 68 (1982), S709.

8) E. A. Mousa, D. Senk, A. Babich and H. W. Gudenau: Ironmaking Steelmaking, 37 (2010), 219.

9) E. A. Mousa, D. Senk and A. Babich: Steel Res. Int., 81 (2010), 706.

10) M. Isobe, T. Sugiyama and S. Inada: Proc. 6th Int. Iron and Steel Cong., ISIJ, Tokyo, (1990), 439.

11) S. Matsuhashi, H. Kurosawa, S. Natsui, T. Kon, S. Ueda, R. Inoue and T. Ariyama: ISIJ Int., 52 (2012), 1990.

12) K. Anan, T. Nagane, L. Nagata, Y. Ogata, M. Honda and M. Isobe: CAMP-ISIJ, 12 (1999), 234

13) M. Sawayama, K. Miyagawa, K. Nozawa, Y. Matsui and K. Shibata: Proc. 5th Int. Cong. Science and Technology of Ironmaking, The Chinese Society for Metals, Beijing, (2009), 659.

14) Y. Togino, M. Sugata, I. Abe and M. Nakamura: Tetsu-to-Hagané, 65 (1979), 1526.

15) M. Sasaki, K. Ono, A. Suzuki, Y. Okuno, K. Yoshizawa and T. Nakamura: Tetsu-to-Hagané, 62 (1976), 559.

16) K. Koch, J. Lamut, H. J. Renner and H. Schliephake: Stahl Eisen, 102 (1982), 411.

17) P. F. Nogueira and R. D. Fruehan: Metall. Mater. Trans. B, 35B (2004), 829 .

18) T. Yamada, M. Sato, N. Miyazaki, H. Shimamura and S. Taguchi: Kawasaki Steel Giho, 6 (1974), 16.

19) Y. Kashihara, Y. Iwai, T. Sato, N. Ishiwata and M. Sato: ISIJ Int., 55 (2015), 1237.

20) T. Sato, T. Nouchi and M. Kiguchi: Kawasaki Steel Giho, 29 (1997), 30.

21) T. Orimoto and M. Naito: CAMP-ISIJ, 13 (2000), 894

22) A. Shigemi: Seisen Handbook, Chijin syokan, Tokyo, (1979), 182. 